\title{
Aproximaciones comparativas respecto al diálogo literario: Lo Somni de Bernat Metge (1399) y el Diálogo de la lengua de Juan de Valdés (1535)
}

\author{
JUdiTH DE DIEGo MuÑOZ, UCM \\ jddiego@estumail.ucm.es \\ Recibido: abril del 2011. Aceptado: junio del 2011.
}

\begin{abstract}
Resumen: Atención a los aspectos que acercan o alejan Lo Somni de Bernat Metge (1399, inédito hasta el año 1889, por J.M. Guardia) y el Diálogo de la lengua de Juan de Valdés (1535, editada por primera vez en 1736); distantes entre sí por casi dos siglos. Evolución desde el primer humanismo peninsular hasta el Renacimiento literario español, como clave para comprender el tratamiento del género dialogístico, los personajes y la temática en pos de una finalidad humanista oculta en el estilo y la alteridad de estos dos autores.
\end{abstract}

Palabras clave: Literatura comparada catalana-castellana. Diálogo humanista. Bernat Metge y Lo Somni. Juan de Valdés y el Diálogo de la lengua.

Resumen: Atenció als aspectes que apropen o allunyen Lo Somni de Bernat Metge (1399, inèdit fins el 1889, per J.M. Guardia) i el Diálogo de la lengua de Juan de Valdés (1535, editat per primera vegada el 1736); separats per gairebé dos segles. Evolució des del primer humanisme peninsular fins al Renaixement literari espanyol, com a clau per comprendre el tractament del gènere dialogístic, els personatges i la temàtica rere una finalitat humanista

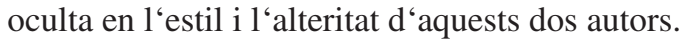

Paraules clau: Literatura comparada catalana-castellana. Diàleg humanista. Bernat Metge i Lo Somni. Juan de Valdés i el Diálogo de la lengua.

\section{ORALIDAD Y VERACIDAD DIALOGÍSTICA: DISPOSICIÓN Y ESTILO}

«Planifico al mismo tiempo que produzco». Alguien, en alguna conferencia, muy recientemente, pronunció esa frase, haciéndola suya y reiterando que era una de las características fundamentales de nuestro espectro cultural. Pero, ¿sólo del nuestro? Al estar encuadrado este análisis dentro de la Literatura catalana comparada, y en este caso, con la castellana, me pareció importante esta afirmación categórica de la no planificación del lenguaje oral, especialmente, en 
las lenguas romances, caracterizadas por ser ambas PRO-DROP ${ }^{1}$. Este rasgo, de tan marcada oralidad en su expresión, es hasta tal punto empleado que llega a plasmarse en testimonios literarios desde los primeros albores de ambos romances, cuanto más, según avanzan en su proceso evolutivo, permitiéndonos encontrar abundantes ejemplos en el territorio peninsular. Véase, por ejemplo, en el valdesiano Diálogo de la lengua (1535) ese supuesto desorden de los temas a tratar, la no sistematización o la arbitrariedad de las cuestiones elegidas a debatir.

Valdés - [...] yo os digo lo que se me ofrece; ponedlo vosotros en el lugar que quisiéredes. (Pág. 147)

Pese a la improvisación de la lengua, se nota en la obra de Juan de Valdés un buen gusto a la hora de elegir los términos con los que dará claridad y sencillez a su obra dialogística. Valga remarcar aquí el deleite de los trecentistas italianos en cribar minuciosamente el léxico con la naturalidad discursiva como meta. Igualmente, el alcance e inflexión que esto tiene sobre Valdés. Así pues, se justifica el uso y cariz que el autor atestigua a los refranes empleados por el vulgo «lo mejor que los refranes tienen es ser nacidos en el vulgo» (Pág. 127); «Bien aya quien a los suyos se parece», «Adondequiera que vayas, de los tuyos ayas» [...] y «Quien no arrisca no aprisca» (pág.195); los neologismos de la época (que sirven a la vez como marca de las modas lingüísticas del momento histórico), los sinónimos y la metáfora.

De sobra sabemos que la lengua, además de este rasgo de no planificación, conlleva, por definición y de manera innata, un proceso de evolución imparable; el privilegio de ser voluble en cuanto al antojo de quienes hacen de ella útil de comunicación. Las dos obras que tenemos como objeto de estudio, emplean la lengua como instrumento, tanto de autogestación, como de elemento de análisis; propiedades en las que, más tarde, nos detendremos. El diálogo humanista catalán de Bernat Metge, Lo Somni, «si ya existía como libro, en forma adecuada para ser divulgado, el primer cuatrimestre de $1399 »^{3}$, no fue editado hasta 1889, gracias a J. M. Guardia. Otro tanto ocurrió con el Diálogo de la lengua de Juan de Valdés, obra que no vio la luz hasta 1736, pese a estar terminada a mediados de 1535. Y aún así, pese a esta tardanza de publicación, nos resulta, cuanto menos curioso, el alto grado de vivacidad y vigor expresivo perdurable en ambas a lo largo de los siglos. Quizá sea esto lo que hace tan atractivo dichos diálogos: la fidelidad hacia el habla de las diferentes épocas. Veracidad inque-

${ }^{1}$ PRO-DROP, Pronoun.dropping o «pronombre que cae», denominación que reciben aquellas lenguas en las cuales, cierta clase de pronombres pueden ser omitidos cuando son inferidos mediante la pragmática oracional o contextual. También conocido como «metáfora cero». Este rasgo se da en todas las lenguas romances, excepto en francés.

2 Para la extracción de citas de Diálogo de la lengua utilizaré la edición que la profesora C. Barbolani hizo para la editorial Cátedra, 1998.

${ }^{3}$ Batllori (1959: 135). 
brantable y necesaria a la que el Humanismo, y luego el Renacimiento, otorgaba valor de ley.

Y referente a la autenticidad de reproducción de la lengua hablada, encontramos otro influjo humanista en el renacentista Diálogo de la lengua: la no diferenciación entre lengua hablada y escrita que empezó a tenerse en cuenta con Erasmo - quien compartía correspondencia con el propio Valdés—: «...el estilo que tengo me es natural, y sin afectación ninguna escrivo como hablo; solamente tengo cuidado de usar vocablos que signifiquen bien lo que quiero dezir, y dígolo quanto más llanamente me es posible, porque a mi parecer en ninguna lengua stá bien el afectación» (Pág. 233). Clara muestra de la preferencia por escribir según se habla (no olvidemos el empaque metalingüístico de la obra) nos viene dada por los rasgos de oralidad. Detalle que también dotará al texto de veracidad para con el lector y su mayor aceptación del mismo. Premisas básicas para la buena comunicación, fin último de esta obra, porque «la facilidad y la llaneza andan siempre con la elegancia.» Busca Valdés la brevedad y precisión de la lengua: «todo el bien hablar castellano consiste en que digáis lo que queréis con las menos palabras que pudiéredes, de tal manera que, esplicando bien el conceto de vuestro ánimo, y dando a entender lo que queréis dezir, de las palabras que pusiéredes en la cláusula o razón no se pida quitar ninguna sin ofender a la sentencia della, o al encarecimiento, o a la elegancia.» (Pág. 237). Sentencias como «El estilo en la verdad va bien acomodado a las personas que hablan.» (Pág. 255) nos recuerda el decorum linguae extraído del espíritu renacentista, herencia directa del Humanismo. Premisas con las que queda demostrado el empeño del autor por abogar, desde la estructura de la obra, por dichos índices encontrados en la lengua oral. Por otro lado, tenemos Lo Somni de Bernat Metge con parlamentos más largos, introducidos o intercalados en verbos de lengua. Algo que se opone diametralmente a la obra valdesiana, donde se prefiere la rapidez extrema, casi teatral, de introducir cada parlamento mediante el nombre del interlocutor. Sin pausas, sin voz del narrador que comente, a modo de aparte, se nos da así una sensación de cotidianeidad y fluidez verbal propia de cualquier charla amena y desenfadada.

Antes de desvelar las claves diferenciadoras, hemos de remarcar que, si bien el diálogo metgiano peca de lentitud, extensión y repeticiones (como la coletilla discursiva «dix ell ${ }^{4} »$ ), no podría entenderse de otra manera. Un diálogo desnudo y escueto le hubiera impedido dar vida a la acción; mientras que el acotar las actitudes y reacciones de los interlocutores nos ofrece cierto descanso, matizando pausas propias del diálogo. Aún así, seguimos encontrando breves fragmentos en los que el dialogar se realiza más pausado, con un aire más discursivo, que se aviva con frases enlazadas entre sí. Algo que, en palabras del profesor Batllori, «sembla les Capcaudades trovadoresques» $»^{5}$. Así, la exposición metgiana del diálogo, introduciendo la palabra-voz de los personajes directamente, sin recurrir a la técnica teatral valdesiana del nombre de pila; además de

${ }^{4}$ Para la extracción de notas de Lo Somni utilizaré la edición bilingüe de la profesora J. Butiñá para el Centro de Linguiística Aplicada ATENEA, 2007.

${ }^{5}$ Riquer (1959:160). 
la instauración de la lengua vulgar para un diálogo de corte platónico-ciceroniano, remarca la originalidad y dominio de composición y transposición de fuentes latinas en Bernat Metge.

La elección de la lengua materna para la creación de su obra, responde al imperativo estético de redacción utilizado por Ramon Llull en sus obras de mayor divulgación, como fueron su Llibre del gentil i els tres savis (1274-76) o el propio Blanquerna (1283). Y es comprensible si tenemos en cuenta el fin con el que se escribe Lo Somni metgiano. Más aún si conocemos el escepticismo que recorría, a finales del siglo XIV, la alta nobleza catalana, lectora voraz de traducciones y tratados filosóficos en lengua vulgar. Al igual que ocurre con el Diálogo de Valdés, quien aboga por un correcto castellano llevándolo al terreno más práctico, como es la composición autogenética de un diálogo, Metge perseguía el máximo entendimiento de su doctrina; la defensa de su objetivo.

Sintetizando lo anterior, la siguiente tabla comparativa de elementos lingüísticos pone de manifiesto un conjunto de premisas, dando muestra de los cuatro aspectos básicos para el contraste entre los estilos dialogísticos diferenciadores entre ambas obras.

\begin{tabular}{|l|l|l|}
\hline & \multicolumn{1}{|c|}{ Lo Somni } & \multicolumn{1}{c|}{ Diálogo de la lengua } \\
\hline Parlamentos & $\begin{array}{l}\text { Más extensos. } \\
\text { Mayor sensación de tratado. } \\
\text { Uso de una retórica extensa. }\end{array}$ & $\begin{array}{l}\text { Breves. } \\
\text { Mayor sensación dialogística. } \\
\text { Brevedad y concisión retórica. }\end{array}$ \\
\hline Empleo de verbos dicenda & $\begin{array}{l}\text { En la introducción de parla- } \\
\text { mentos. }\end{array}$ & $\begin{array}{l}\text { Carente de ellos. Introduce los } \\
\text { parlamentos mediante los } \\
\text { nombres de pila de los interlo- } \\
\text { cutores. Rasgo de teatralidad. }\end{array}$ \\
\hline Tiempo-duración interna & $\begin{array}{l}\text { Mayor lentitud oral en el es- } \\
\text { quema Pregunta-Respuesta. }\end{array}$ & $\begin{array}{l}\text { Mayor vivacidad en la inter- } \\
\text { vención de interlocutores. }\end{array}$ \\
\hline Tiempo-duración externa & $\begin{array}{l}\text { Mayor sensación de prolon- } \\
\text { garse en el tiempo. }\end{array}$ & $\begin{array}{l}\text { Mayor sensación y adecuación } \\
\text { al tiempo externo del diálogo. }\end{array}$ \\
\hline
\end{tabular}

\section{¿DIÁLOGO O MONÓLOGO? EL FRAGMENTARISMO DEL «YO»}

Según T. Albaladejo, el diálogo es una unidad lingüística fundamental. Como estructura comunicativa primaria, refiere la comunicación lingüística en grado pleno. Algo contrario al monólogo, unidad secundaria y derivativa de la comunicación. Sin embargo, éste posee una dimensión dialogística en tanto en cuanto establece una relación entre dos o más comunicantes, y, por tanto, una expresión con carácter monológico forma parte de una cadena de monólogos que alternativa y sucesivamente, se ofrecen respuesta unos a otros. ${ }^{6}$ Dicha premisa

\footnotetext{
${ }^{6}$ Albaladejo (1982: 225-248).
} 
del monólogo que se extiende y habla consigo mismo, respondiéndose, nos llevó a pensar en los diálogos que vamos a cotejar, ya que una de las cuestiones primordiales en estos diálogos literarios peninsulares es el desdoblamiento que sufre, intencionadamente, el autor al convertirse en personaje. Esta ruptura del «yo-autor» y su disgregación en «yo-personaje» responden al montaje en cadena de monólogos del que hablaba. El «yo-autor» se divide en disímiles y nace la polifonía discursiva. Ya no es un tratado ejemplarizante o de intenciones. Sino el intercambio oral; la dramatización de un discurso monocorde: el diálogo. Y, sin visos de conformidad, fragmenta de nuevo esas dos voces, creando el coro dialogístico. Sin extralimitarse, una vez metido en el texto con la voz del personaje principal, se multiplica en varias voces que, mediante su ingenio, son meros instrumentos para expresar su opinión al respecto del tema del debate o aplicar la doctrina que le mueva a escribir. Mientras un par de voces que, ¡no olvidemos!, siguen siendo el propio autor discutiendo consigo mismo, el resto escucha, juzga e interviene. Acudimos a la conversación, a la controversia oral. Tal desdoblamiento corresponde a la imagen del escritor que se piensa a sí mismo pensando en el interés que desee remarcar en su obra. Este hacerse a sí mismo y plasmarse en papel mientras está ocurriendo, nos lleva a la Gestación vivípara unamuniana, o autogénesis literaria, mediante la cual, el diálogo va formándose a sí mismo, siendo la obra, un reflejo del acto de creación literaria. ${ }^{7}$ En el diálogo castellano vemos una doble vertiente gracias a la figura del escribano escondido. En primer lugar, un Valdés-personaje participante del diálogo que se está produciendo; y, en segundo lugar, un Valdés-autor que está formando el diálogo, en movimiento, al mismo tiempo que va añadiendo palabras para la solución del mismo. Es la representación escrita de cómo se hace un diálogo. Es, casi, metaliteratura o teoría literaria. Y, si así lo creemos, casi teatral. Tal acento histriónico se aprecia ya en la obra de Metge, aunque de manera muy leve debido a lo temprano de su escritura. No obstante, durante un parlamento de Joan I, éste es interrumpido por Tiresias, dejando a medias su discurso y dando paso, muy torpemente, al personaje del ciego:

«e que ab diligent cura tenga a prop ma filla e sua, car la innocència e virtuts d'aquella són molt plasents a Nostre Senyor Déus, de la qual exirà...

E tantost lo prohom ab la barba longa féu-li senyal ab lo bastó que callàs.» (Pág. 154)

Esto mismo, pero de manera más evolucionada, podemos apreciarlo en el escrito valdesiano, mediante pequeños movimientos que el propio Valdés-personaje realiza, como por ejemplo, la salida del escenario al principio de la obra:

Valdés- [...] hazedlo assí, y entre tanto me salliré yo al jardín a tomar un poco de aire.

Marcio- [...] andad con Dios, que presto os llamaremos.

${ }^{7}$ Avalle-Arce (1978: 67-69). 
Torres-Pues avemos cogido y prendado a Valdés, aún no lo dexemos de ninguna manera sin que primero lo esaminemos hasta el postrer pelo [...]

Coriolano-Yo desseo siempre prevenir por no ser prevenido, y assí querría que pusiéssemos escondido en algún lugar secreto un buen escrivano, apra que notasse los puntos principales que aquí se dixessen, porque podría ser que con este principio engolosinássemos a Valdés de tal manera que le hiziéssemos componer qualque diálogo de lo que aquí platicaremos.

Marcio- $-[.$.$] poned a messer Aurelio, entendido en entramas lenguas, y or-$ denadle lo que ha de hazer; mientras que yo voy a llamar a Valdés. (Págs. 129-130-131)

Este tipo de entradas y salidas, de comentarios entre personajes a escondidas del protagonista, de la introducción de otra figura que permanecerá sin ser visto por él durante toda la obra hasta el descubrimiento final, están, a mi parecer, más próximas a las comedias de enredo del siglo XVII que al puro género dialogístico. Lo que no nos extraña si pensamos en los pasos de Lope de Rueda, en plena gestación y a punto de ser representadas en las corralas de todo el país.

\section{UN «YO» POLIFÓNICO: RELACIÓN ENTRE INTERLOCUTORES}

Hablábamos previamente de cierto desdoblamiento. El fragmentarismo del «yo-autor» en los distintos personajes-copartícipes del diálogo; detalle a tener en cuenta para descubrir la verdadera intención y, por tanto, posición del autor respecto al tema sobre el que se conversa. De la misma manera, mientras Metge intenta dialogar con las presencias de sus interlocutores sobre la inmortalidad del alma y la salvación de Joan I, como propósito para salvarse él mismo; Valdés se encuentra en parlamento directo con sus tres «amigos» — consideración familiar conversacional que aporta veracidad al texto-. Desde el punto de vista de un conocedor de la lengua —nótese la preocupación pedagógica propia de erasmistas, donde destaca el valenciano Joan Lluís Vives (1493/1540) - trata Valdés diferentes aspectos sobre el buen uso durante la expansión que el romance castellano tuvo durante los Siglos de Oro. Y, quién sabe, si también le sirvió como arremetida contra la ya obsoleta Gramática de la lengua castellana de Antonio Nebrija (1492). Por tanto, en el texto metgiano, el autor era muy consciente de que, si quería conseguir el objetivo que le movió a producir su Somni, éste debía poseer varias lecturas posibles para agradar tanto a sus detractores, como a quienes lo apoyaban. Y para ello, crea un «yo-personaje» protagonista que va cambiando, y hace cambiar de posición según el interlocutor y dependiendo de la postura que uno y otro pretendan defender o criticar. Con el diálogo de Valdés ocurre algo muy similar. El «yo-personaje» protagonista creado por el autor entra directo al hecho dialogístico, dando la voz y la palabra al resto de personajes. Estos, en mayor o menor medida, nos ofrecerán la opinión del autor y su confrontación. Este enfrentamiento entre el «yo-artista» y el «yo-pensador-crítico», desemboca en una «iluminación final», más o menos positiva, mediante la intervención de otro personaje. En el caso de Metge, al autor-per- 
sonaje es Tiresias quien le abre los ojos ante la realidad ${ }^{i} O$, de quanta calige de tenebres són abrigats los desigs dels hòmens! [...] Bé faràs — dix ell — com tot ho sabràs. [...] Trenca lo pont per on est passat, en manera que no et sia possible retornar [...] e pus en la tempestuosa mar has viscut, fé ton poder que muires en segur e tranquil.le port.» Lo Somni (Págs. 186-224-282). Mientras que respecto a Valdés, es Marcio quién le abre los ojos al final de la obra.

El diálogo, como género híbrido que testimonia actos de la vida y expresa inquietudes personales, se plantea como abanico de posibilidades para el receptor. Pero también para el emisor, quien puede distribuirse en una serie de papeles o de diferentes tipos de «alter ego» que lo contengan o reflejen en distinto grado, con frecuencia de manera enfrentada. Este recurso de animación y movimiento escénico ya comentado, ayuda a la despersonalización del autor aparentando mayor imparcialidad respecto a los enjuiciamientos que allí se hacen. Atestigua, al contrario, una mayor autoridad a sus palabras. Esta manera de «esconderse» en otros y no declarar de forma explícita, es, en realidad, un claro apelarse a sí mismo. Y este juego le dota de una elevada autoridad, procedente de la distancia que de sí hace el autor, desdibujando su «yo», creando personajes casi con autonomía de entidad propia. Es en este punto donde comienza la posibilidad de una múltiple lectura de la obra. Por tanto, dicho fragmentarismo del «yo-autor», provoca una compleja red de relaciones entre personajes. De este entramado dependerá la visión-lectura que se tenga (o que se nos quiera dar) de la obra. Así, el autor transmite la necesidad de un lector, sino cómplice, según se propondrá en la novela moderna (aquel «lector macho» tan polémicamente bautizado por Cortázar), al menos sí despierto y audaz, capaz de descubrir el verdadero camino a seguir para la correcta interpretación de correspondencias entre los diversos «yo-personajes» y la voz del autor.

\section{1 -Relación personajes-temático de Diálogo de la lengua ${ }^{8}$}

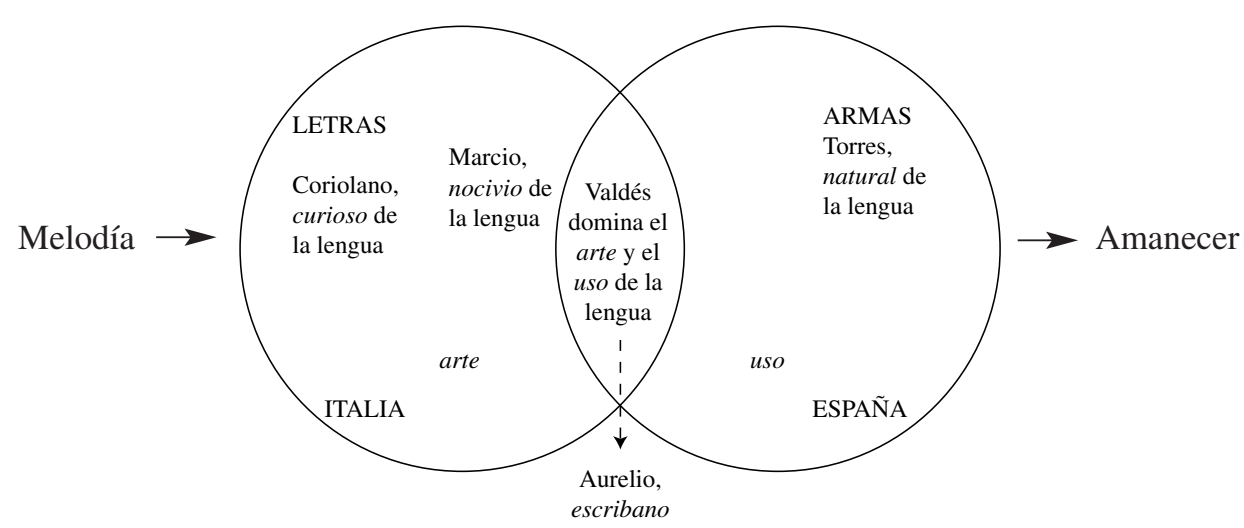

${ }^{8}$ Esquema de relación de personajes extraído de la edición de Barbolani (1998: 58). 
2 -Relación de personajes-temático en Lo somni.

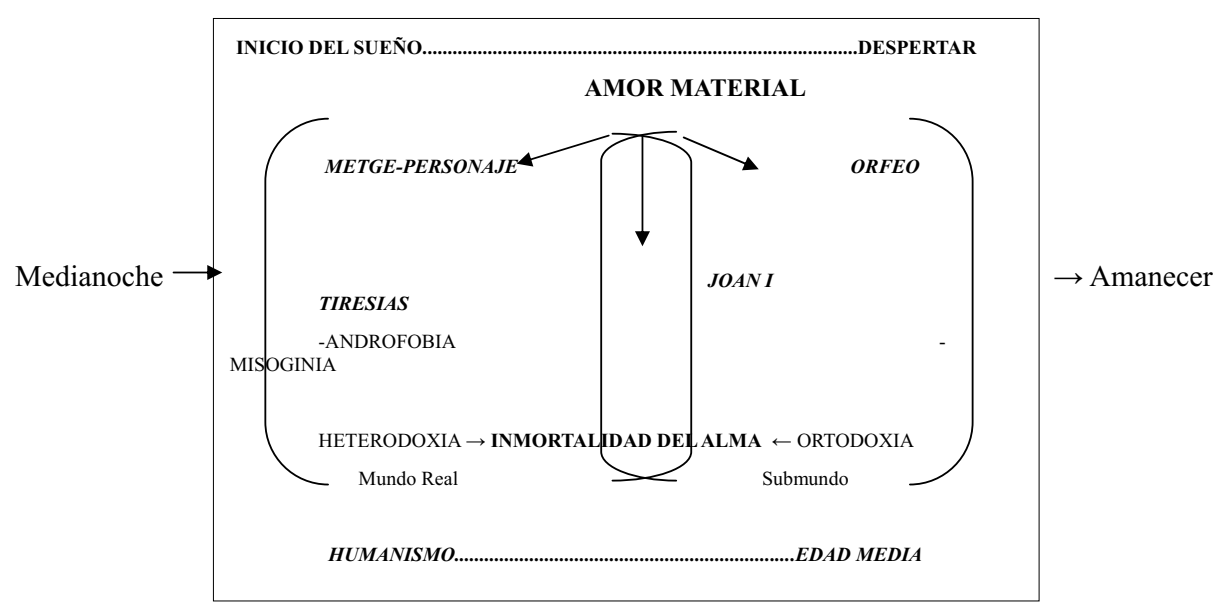

En los esquemas anteriores se proponen una serie de relaciones entre personajes y temas tratados en ambas obras. Así, el primero de ellos, a propósito del texto de Valdés, y debido a la profesora C. Barbolani, se aprecia una dualidad de espacios (España-Italia), puesto en contacto a través de la figura-intermediario de un «Valdés-personaje»; así como la bipartición temática de «Armas-Letras» tan asociada ya al Humanismo y posterior Renacentismo. Ambos aspectos, posicionan personajes, encontrándose, una vez más, el «Valdés-personaje» como eje central articulador. Asimismo, el marco temporal externo de la acción iría desde el mediodía hasta la medianoche. Por otro lado, en el segundo cuadro, proponemos por nuestra parte que el texto de Metge ofrece, del mismo modo, esa dualidad espacial entre el «Mundo Real» y el «Submundo», cuya entronque sería la figura de Joan I. En cuanto a los temas como la androfobia o la misoginia; la heterodoxia o su contrario - férreamente defendido por Tiresias- etc. son dichas inferencias las que emplacen a los personajes en un lado u otro, según sea su actitud argumentativa o su pertenencia a uno de los dos mundos encontrados durante el sueño. Respecto al tiempo externo de la acción, ésta vendría acotada en su inicio por la medianoche y el amanecer cuando toca fin. Y, si queremos seguir completando con más datos relacionales, podríamos apuntar que la Medianoche, el Inicio del sueño y el Humanismo, estarían diametralmente opuestos al Amanecer, el momento de Despertar del suelo y la Edad Media.

Las relaciones que unen o disocian estas dos triadas de elementos quedan más que justificadas a lo largo de la obra, esperamos, de este estudio. Pero, por si nos pareciese poco todo lo que venimos diciendo de Lo Somni, en el segundo cuadro referente a éste encontramos la posibilidad de contar con una figura extra. Ésta no es otra que, la llamada «Príncep dels mals sperits». Merece mención ya que, posiblemente, constituya un quinto «yo-personaje» depositario y portavoz de la opinión del autor. Así, en el Llibre II de Lo Somni, durante la celebra- 
ción del juicio sobre el alma de Joan I, el diablo, hace de abogado de los oponentes de Martí L'Humà. $\mathrm{O}$, lo que es lo mismo, defensor de la camarilla humanista de Bernat Metge. En su contra, y como suprema defensora de la tradición, sublimación de vida y redención, se alza la Virgen. Partiendo de esta base, Helena Guzmán plantea la posibilidad de cierta influencia griega (idea fundamentada en el influjo helenístico que trajo a la península Juan Fernández de Heredia durante el reinado de Pere el Cerimoniós). El escritor Semónides de Amorgos (siglo VII a. C.) en su Yambo de las mujeres, se basa en la lírica popular ligada a rituales de nacimiento y muerte, para realizar una detallada descripción animalizadora de la mujer. Harta parecida, por cierto, a la expuesta por Tiresias en el Llibre III de Lo Somni. De esto, llevado a la escena del juicio, se podría obtener el enfrentamiento de figuras femeninas. Si se añade la posible ascendencia helenística, vemos, por un lado, la redentora imagen de la Virgen, mujer idealizada; y, en contraposición, la Eva griega, Pandora. La mujer-diablo. ${ }^{9}$

Por todo ello, esta relación entre personajes marca similitudes y diferencias entre diálogos, los cuales, pese al diverso tratamiento que hace de los interlocutores, deja bien claro que no son más que meras piezas huecas que el autor rellena con su opinión confrontada o no y utiliza, posicionándolas en tal o cual lado de su opinión, para expresar la plenitud de su pensamiento acerca del tema enjuiciado. Por tanto, como anunciábamos previamente, el lector ha de tener en cuenta las relaciones entre personajes. No ya por la diversidad de la interpretación de la historia (pues casi no hay acción); sino por revelar el auténtico posicionamiento y la opinión que el autor adopta frente al diálogo. No obstante, todos los interlocutores (que en realidad, no son más que dos: Metge y Valdés, respectivamente), cumplen con una serie de «requisitos» del diálogo literario $^{10}$ :

- Posesión de un solo productor externo, forma y efectivo. Esto es, el propio autor del texto.

- Los interlocutores que aparecen en ambos textos son emisores y receptores internos, comunicantes textualizados. En ocasiones, se emplean personajes históricos para dar veracidad. Véase el caso de Joan I, Coriolano Martirano, obispo de San Marco y su sobrino Marcio.

- Ambas obras, como cómputo global, van dirigidas a receptores del diálogo externos a los que, interiormente, se dan cita en la obra (incluso siendo, como en nuestro caso, personajes históricos reales).

- Estos interlocutores internos se comunican conscientemente entre ellos, pero también con los receptores externos - lectores-. Esta comunicación se nos da mediante las expresiones presentadas, directa o indirectamente, por la voz del narrador (aquí, y de manera intrínseca, en los parla-

\footnotetext{
9 Guzmán (2009).

10 Albadalejo (1982: 231-232).
} 
mentos de Metge-autor-personaje y Valdés-autor-personaje). Esto, permite una unión e identificación entre la realidad de la obra con la realidad vivida por los lectores-receptores del mensaje a revelar por el autor.

Para concluir estas reflexiones sobre el fragmentarismo en los diálogos de Bernat Metge y Juan de Valdés, no puedo dejar de anotar aquí, a modo de brevísima evolución o, quizá, anécdota histórica, la continuidad y pervivencia de esta técnica narrativa en nuestra literatura. Tanto es así que, en obras de prosa vanguardista como Pero... ¿hubo alguna vez once mil vírgenes? de 1931 vemos este desdoblamiento del autor-personaje llevado al extremo desde la propia dedicatoria de la obra:

A ENRIQUE JARDIEL PONCELA, MI

MAYOR ENEMIGO, CON LA ADHESIÓN, LA SIMPATÍA Y EL AFECTO DE ENRIQUE JARDIEL PONCELA. ${ }^{11}$

\section{RETRATO, ESPACIO Y TIEMPO DIALOGÍSTICO}

La ambientación parca en detalles de ambas obras es pareja a la descripción de personajes:

«Estant així, a mi aparech, a mon viyares, «el señor Torres, como hombre nacido y un hom de mitge statura, ab reverent cara, criado en España presumiendo de saber la vestit de vellut pelós carmesí sembrat de corones dobles d'aur, ab un barret vermell en lo cap. E acompanyaven-lo dos hòmens de gran statura, la un dels quals era jove, fort bell e tenia una rota entre les mans; e l'altre era molt vell, ab longa barba e sens ulls, lo qual tenia un gran lengua tan bien como otro, y yo, como curioso della desseando saberla assí bien escribir como la sé hablar, y el señor Coriolano como buen cortesano quiriendo del todo entenderla»

Diálogo de la lengua (pág. 119)

bastó en la mà...»

Lo somni (pág. 56)

Vemos que en Lo Somni, se nos hace un retrato más plástico que en el diálogo de Valdés, quien se conforma con darnos rasgos contrastivos de sus tres interlocutores respecto al conocimiento de la lengua. Retratos, pues, más psicológicos que los anteriores. Esto se nos explica mediante la evolución que tuvo el género del retrato literario desde la Edad Media, de corte biográfico y

${ }^{11}$ E. Jardiel Poncela, Pero... ¿hubo alguna vez once mil vírgenes? Ed. Luis Alemany. Madrid: Cátedra, 1968. 
vehículo de exempla, hasta el Renacimiento. Aquí la selección de datos previa al periodo humanista provoca la predilección de reflejar las acciones, la moral o el carácter del personaje retratado, en detrimento del aspecto físico como elemento base de la efigie literaria.

El espacio en el que el autor renacentista encuadra sus obras sirve como marco resolutivo para la solución oral y escrita del diálogo; por lo que se nos presenta como una tira de imágenes lineal, a modo de tebeo, pero sin apenas profundidad entre personajes y entorno. Algo que contrasta fuertemente con el punto de fuga y dimensionalidad que podemos apreciar en el desarrollo del diálogo metgiano o en los diferentes momentos en los que éste, a pinceladas, «dibujaba» su galería de retratos. Él los describe; habla de y con ellos; los perfila. Y nos los presenta como un Velázquez entre sus meninas. Empero, si respecto al espacio Metge parece aventajar a Valdés, no ocurre de igual manera en el tiempo. Vemos que, mientras Valdés hace referencia a conversaciones anteriores «tornemos a hablar en lo que comencé a deziros esta mañana» (Pág. 117) y a un intercambio epistolar precedente al diálogo «siempre hallábamos algo que notar en vuestras Cartas» (Pág. 120); Metge alude a la ya archiconocida estancia en Mallorca. Por tanto, pretérito traído al presente dialógico. Y mezclado con una proyección futura, expresada al final de ambas obras:

\begin{tabular}{|c|c|}
\hline $\begin{array}{l}\text { "Una cosa solament vull de tu: que res que } \\
\text { a present hages vist o hoüt no tengues celat } \\
\text { a mos amichs e servidors; car, ultra lo pla- } \\
\text { er que ahuran de mon estament, los ne se- } \\
\text { guirà gran profit; especialment, per tal } \\
\text { com seran certs de moltes coses (en que } \\
\text { solament alguns d'ells dubten, mas la ma- } \\
\text { jor part dels hòmens; e signantment igno- } \\
\text { rants, desl quals és gran multitud en lo } \\
\text { mon). } \\
\text { E si en escrits ho volies metre, ja se'n se- } \\
\text { guiria major profit en lo temps esdevenidor } \\
\text { a molts, de què hauries gran mèrit.» } \\
\text { Lo Somni (págs. 150-152) }\end{array}$ & $\begin{array}{l}\text { «Marcio-Aurelio, daca lo que as escrito. } \\
\text { [...] Antes porque veo el provecho y no el } \\
\text { inconveniente, pienso en darlos a todos los } \\
\text { que lo querrán, y aun, si me pareciere lo } \\
\text { haré imprimir. } \\
\text { Pacheco-Avéis de saber que lo que todo } \\
\text { os pedimos merced es que, tomando esto } \\
\text { que stá anotado de lo que aquí avemos ha- } \\
\text { blamos, lo pongáis todo por buena orden y } \\
\text { en buen estilo castellano. } \\
\text { Diálogo de la lengua (págs. 262-263) }\end{array}$ \\
\hline
\end{tabular}

Estas propuestas de futuro, también traídas hacia el presente de la obra, o si se prefiere, futuro que arranca desde ese presente dialogístico, proporciona un final dinámico y circular a la obra, asegurándose una vida futura para el texto. Respecto a la relación entre el tiempo y el espacio de ambas obras, podemos atisbar que, mientras el sueño ocurre en el Castel Nou de Barcelona, «la presó», comenzando a medianoche y postergándose hasta el amanecer, Valdés, sitúa la acción a las afueras de Nápoles, en un tipo sobremesa que se extiende hasta el anochecer. 


\section{INTENCIONALIDAD: COMPOSICIÓN, MENSAJE, DESTINATARIO}

El mensaje transmitido en las obras, conlleva una autoría consciente del verdadero fin de la obra. Esto es, la intencionalidad que hay detrás de cada texto, está contenida en todos aquellos juicios de valor que podamos adjudicar a Metge o Valdés, respectivamente. Así, en el primer caso, Bernat Metge, para su propia salvación, se sirve de la divulgación de la nueva corriente humanista que sólo será advertida por el buen lector, como señalábamos arriba. Quién no lo sea, se conformará con una falsa conversión y el acatamiento moral de la doctrina imperante. Por otro lado, Juan de Valdés, opta por una divulgación del arte de la lengua romance vulgar para provocar un asentamiento y un correcto uso de ella, como instrumento de expansión y proyección futura social, política y económica de sus propios intereses y los de la Corona. Téngase en cuenta que, una de las mayores preocupaciones, tanto de humanistas como de erasmistas, fue la repetida insistencia en la labor pedagógica y la fidelidad y correcto uso de la lengua. Pero no olvidemos que Valdés, gracias a la intermediación de su hermano Alfonso, mantuvo una relación epistolar con Erasmo de Rotterdam (14661536). Por tanto, ¿podríamos preguntarnos que, a la par que el buen uso del romance, está intentando divulgar una doctrina de influjo humanista mediante las técnicas compositivas del nuevo diálogo renacentista? Desde aquí, la intencionalidad compositiva de cada autor da cabida a una de las diferenciaciones genéricas de cada diálogo. Mientras que Lo Somni sería un híbrido del diálogo ciceroniano-lucianesco. La elaboración mayéutica del método socrático pregunta-respuesta y argumentación a través de la sátira hacia ciertos autores (como, por ejemplo, San Gregorio); además de lo característico de su ubicación: en «la presó», o lugar de reclusión y estudio del protagonista, representarían este primer tipo. Por otro lado, el Diálogo de la lengua presentaría una composición propia del diálogo lucianesco-erasmista, de síntesis sofista, reconvención de costumbres y, al igual que dijimos antes, tintes satíricos empleados para la crítica. Mediante la caracterización del diálogo y sus personajes, manejados ambos con el fin de expresar la inquietud del autor y su época, convertido en un ejercicio de introspección, esta obra emitida para un conjunto, en la que se funde voz y escritura. Como último detalle a contrastar, queríamos indicar aquí la variante del diálogo platónico que, siguen Bernat Metge y Juan de Valdés. Para Platón, se inicia un camino o viaje de iniciación. En él encuentra a los futuros interlocutores con los que tendrá, de manera mayéutica, un diálogo, el que, a su vez, reflejaba la ida y venida de un saber a otro a lo largo de la vida. Tras este método de preguntas al interlocutor-discípulo, el personaje continúa su marcha para enunciar nuevos encuentros, nuevos diálogos, nuevos descubrimientos de saber y conocimientos. En Lo Somni de Bernat Metge, tras un inicio muy breve, con prólogo subsumido en la propia obra, en la voz del autor-personaje, se da paso directamente a la venida de los personajes visitadores y, con ellos, al diálogo. Éste se extiende a lo largo de los cuatro libros y toca su fin, casi a la par que el propio sueño. El personaje no inicia de nuevo ningún viaje, como tampoco lo había hecho al principio de la obra. Marca de estatismo hierático medieval, quizá por tener Lo Somni un despertar a la realidad — resolución- de corte negativo; en detrimento de la doctrina que intenta divulgar el autor y que ha quedado expresa durante el desarrollo dialogístico entre los diferentes interlocutores. 
Por último, Juan de Valdés nos introduce de cabeza en la acción. Los interlocutores ya reunidos dan cuenta de un encuentro anterior, esa misma mañana y una relación de cartas con los puntos que se tratarán durante la plática (¿quizá quiera Valdés hacer un guiño con esto sobre un posible prólogo omitido intencionadamente?). Ésta termina en el momento en el que el autor-personaje lo da por acabado y se marcha del lugar donde aconteció el diálogo.

\section{BIBLIOGRAFÍA}

Ediciones Consultadas:

Metge, B. (2007) Lo Somni. Edición bilingüe de Julia Butiñá para el Centro de Lingüística aplicada Madrid, Atenea.

Valdés, J. (1998) Diálogo de la lengua. Edición de Cristina Barbolani, Madrid, Editorial Cátedra. Madrid, 1998.

Valdés, J. (1984) Diálogo de la lengua. Edición de Antonio Quilis Morales. Barcelona, Editorial Plaza\&Janes, Clásicos.

Historia y Crítica Literaria:

Albaladejo Mayordomo, T. (1982) «Pragmática y sintaxis pragmática del diálogo literario.» en Anales de Literatura española, n. ${ }^{\circ} 1,225-248$.

Avalle-Arce, J.B. (1978) Dintorno de una época dorada. Editorial Jose Porrúa Turanzas, Madrid.

Batllori, M. (1987) Humanismo y Renacimiento. Ed. Ariel, Barcelona.

Butinyà, J. (2000): «600 anys de «Lo Somni», el primer diàleg humanístic de la Península.» Revista de Filología Románica, XVII, 295-317.

Butinyà, J. (2003) «De l'Humanisme i del Renaixement» en Revista de lenguas y literaturas catalana, gallega y vasca. Vol. 9, 79-98. También en: http://espacio.uned.es/fez/eserv.php?pid=bibliuned:Llcgv-BDE4D1A9-D820-8223F6EA-D031243F101F\&dsID=Humanisme.pdf

Butinyà, J. (2006): En los orígenes del Humanismo: Bernat Metge, Madrid, UNED, también en: http://www.uned.es/031282/web_despensa/documentos_PDF/jbutinya/Metge_PDF/nouls_libro.pdf ${ }^{12}$

Butinyà, J. (2010) «Lo Somni, en la línea del ensayo moderno.» Transfer: journal of contemporary culture / Institut Ramon Llull, n. ${ }^{\circ}$ 5, 41-61.

12 Butiñá (2006) y la gran mayoría de los artículos citados en la bibliografía y a lo largo del trabajo han sido encontrados, extraídos y consultados a través de la página Web www.dialnet.com debido a la no disposición en archivos físicos. 
Candelas Colodrón, M.Á. (2003) «Modelos dispositivos en el diálogo del siglo XVI español» Anuario de filología hispánica, n. ${ }^{\circ}$ 6, 79-97.

Estébanez Calderón, D. (1996) Diccionario de términos literarios. Madrid, Alianza Diccionarios.

Greiner, H. (2006) Diccionario Akal de literatura general y comparada. Madrid, Akal.

Guzmán, H. (2009) «El viejo tema de la misoginia: ecos de Semónides en Bernat Metge» en eHumanista: Journal of Iberian studies. Vol.13, 277-288.

Hess, R. (1989) Diccionario terminológico de las literaturas románicas. Traducción de J.M. Díaz-Regañón. Madrid, Gredos.

Nomo Ngamba, M. (2008) «Literatura comparada y el análisis de las obras narrativas: el estudio de los géneros, los temas y la forma», Revista electrónica de estudios filológicos, . $^{\circ} 15$.

Prieto, A. (1996) La prisa española del siglo XVI. Vol. I. Madrid, Cátedra.

Riquer, M. de (1959) Obras de Bernat Metge. Facultad de Filosofía y Letras. Universidad de Barcelona. Barcelona. 